This item was submitted to Loughborough's Research Repository by the author.

Items in Figshare are protected by copyright, with all rights reserved, unless otherwise indicated.

\title{
Social isolation and loneliness: prospective associations with functional status in older adults
}

PLEASE CITE THE PUBLISHED VERSION

http://dx.doi.org/10.1037/hea0000437

\section{PUBLISHER}

(c) American Psychological Association

\section{VERSION}

AM (Accepted Manuscript)

\section{PUBLISHER STATEMENT}

This work is made available according to the conditions of the Creative Commons Attribution-NonCommercialNoDerivatives 4.0 International (CC BY-NC-ND 4.0) licence. Full details of this licence are available at: https://creativecommons.org/licenses/by-nc-nd/4.0/

\section{LICENCE}

CC BY-NC-ND 4.0

\section{REPOSITORY RECORD}

Shankar, Aparna, Anne McMunn, Panayotes Demakakos, Mark Hamer, and Andrew Steptoe. 2019. "Social Isolation and Loneliness: Prospective Associations with Functional Status in Older Adults". figshare. https://hdl.handle.net/2134/22377. 
Social isolation and loneliness: Prospective associations with functional status in older adults

Aparna Shankar ${ }^{1,2}, \mathrm{PhD}$, Anne McMunn², PhD, Panayotes Demakakos², PhD, Mark Hamer $^{2,3}, \mathrm{PhD} \&$ Andrew Steptoe ${ }^{2}$, DSc

${ }^{1}$ Population Health Research Institute, St. George’s, University of London

${ }^{2}$ Department of Epidemiology \& Public Health, University College London

${ }^{3}$ School of Sport, Exercise \& Health Sciences, National Centre for Sport \& Exercise Medicine, Loughborough University

Address all correspondence to:

Aparna Shankar

Population Health Research Institute,

St. George’s, University of London

Cranmer Terrace

London SW17 0RE

Email: ashankar@sgul.ac.uk 


\section{Abstract}

Objective: The present analysis aimed to examine the associations of isolation and loneliness, individually as well as simultaneously, with two measures of functional status (gait speed and difficulties in activities of daily living) in older adults over a 6-year period using data from the English Longitudinal Study of Ageing, and to assess if these associations differ by SES.

Methods: Loneliness was measured using the short form of the Revised UCLA scale and an index of social isolation was computed incorporating marital status; frequency of contact with friends, family, and children; and participation in social activities. Measures of functional status were assessed identically at baseline and 6 years later for 3070 participants (mean age 69 years). Wealth was used as an indicator of SES.

Results: In fully and mutually adjusted models, social isolation and loneliness were found to be associated with a decrease in gait speed at follow-up, with stronger effects among more disadvantaged individuals. Loneliness was associated with an increase in difficulties with activities of daily living.

Conclusions: Isolation and loneliness were adversely associated with different aspects of functional status. Interventions to reduce isolation and loneliness may be particularly beneficial for individuals in disadvantaged groups.

Key words: social isolation, loneliness, gait speed, older adults, English Longitudinal Study of Ageing 


\section{Introduction}

There is a considerable body of research indicating the health benefits of a socially integrated lifestyle. Individuals who are isolated have been shown to have higher levels of morbidity and mortality when compared with those who are more socially integrated (Courtin \& Knapp, 2015; Holt-Lunstad, Smith, \& Layton, 2010). While these findings relate to the effects of objective social network characteristics such as contact with friends and family or participation in social activities, similar findings have been reported for 'perceived isolation' or loneliness (Courtin \& Knapp, 2015; Holt-Lunstad, Smith, Baker, Harris, \& Stephenson, 2015). The issue of isolation and loneliness is particularly important for older adults. In the UK, approximately 9\% of older adults report being lonely often (Beaumont, 2013). Levels of isolation are harder to estimate as this construct has been defined and measured differently across studies. However, in the 2011 census, 31\% of adults aged 65 years and over were living alone (Office for National Statistics, 2013). In 2010/2011, about half of older adults in England reported that they did not participate in any civic, leisure or cultural activities and around 5\% reported having either no family, friends or children, or less than weekly contact with these groups (Jivraj, Nazroo, \& Barnes, 2012).

Loss of muscle mass, reduced mobility and disability are common in older age (Brown \& Flood, 2013; Cruz-Jentoft et al., 2010). These changes are not, however, inevitable (Christensen, McGue, Petersen, Jeune, \& Vaupel, 2008). Hence it is important to identify factors that may help maintain physical function in older age. Studies assessing the association between social relationships and physical functioning in older age have largely mixed findings. Higher levels of loneliness were associated with an increase in self-reported difficulties with activities of daily living (ADLSs) such as being able to dress oneself, bathe and eat, mobility problems and difficulty with climbing stairs over a 6-year period in a sample of US adults (Perissinotto, Stijacic, \& Covinsky, 2012). In contrast, loneliness was not 
associated with an increase in either difficulty or dependence in activities of daily living at a 7-year follow-up in the Jerusalem Longitudinal Cohort Study (Stessman, Rottenberg, Shimshilashvili, Ein-Mor, \& Jacobs, 2013). Having a large number of social ties (Unger, McAvay, Bruce, Berkman, \& Seeman, 1999) and participation in social activities have also been linked with less decline in physical function in some longitudinal studies (Buchman et al., 2009; Kanamori et al., 2014; Lee, 2000), with others reporting limited or no significant associations (Avlund et al., 2004; Green, Rebok, \& Lyketsos, 2008). A later analysis by Buchman and colleagues that additionally examined the role of social network size and loneliness found that loneliness was associated with rate of decline in global motor function. Social network size was not, however, associated with either baseline motor function or rate of decline (Buchman et al., 2010). In a cross-sectional study examining the combined effect of marital status and living arrangements, married older adults living with children had the best functional status on measures including difficulties with ADLs and instrumental ADLs while older adults who were unmarried (including widowed/divorced) and living with children reported the worst outcomes (Wang, Chen, Pan, Jing, \& Liu, 2013). Using prospective data from a birth cohort and objective assessments of functioning Guralnik et al. found that never married and married men who remained childless had significantly poorer physical function when compared with married men who had children (Guralnik, Butterworth, Patel, Mishra, \& Kuh, 2009). These associations were not observed among women.

As is clear from above, studies have defined functional status in a range of different ways. Objective or performance-based measures include tests of walking speed, grip strength, and tests of balance, while subjective measures ask participants if they are able to perform certain activities such as bathing, dressing themselves and eating. While related, the two sets of measures capture different aspects of physical function. It has been suggested that most 
performance-based measures reflect functional limitations, i.e. whether or not an individual has the capacity to carry out certain basic actions, with no reference to a specific task or situation. Subjective assessments in contrast, are largely indicative of disability, reflecting the individual’s ability to carry out specific tasks considered important for daily living (Hoeymans, Feskens, van den Bos, \& Kromhout, 1996). It has been suggested that these measures reflect different stages of physical decline with functional limitations foreshadowing the development of disability (Guralnik \& Ferrucci, 2003; Nagi, 1976). Indeed physical performance tests may be indicative of subclinical disease (Cooper et al., 2011; Reuben et al., 2004) and they have been found to be predictive of a range of adverse health outcomes (Abellan Van Kan et al., 2010; Cooper et al., 2011; Studenski et al., 2011). It has been suggested that the two approaches cannot be regarded as being mutually exclusive, and hence a consideration of both may provide a more complete picture of an individual's functional status (Kivinen, Sulkava, Halonen, \& Nissinen, 1998; Reuben et al., 2004).

Previous research has indicated that individuals who are depressed have slower gait speed, although there is some evidence that this association is bidirectional (Demakakos et al., 2013). Higher levels of depression have also been known to be associated with increased difficulties with ADLs and instrumental ADLs (Rozzini et al., 1997). Further, risky health behaviors such as smoking and physical inactivity may be associated with isolation and loneliness (Shankar et al., 2011), and are also associated with poorer functional status (Brach, FitzGerald, Newman, \& et al., 2003; North et al., 2015). Indeed, measures of isolation may to some extent index levels of physical activity and this needs to be taken into consideration when examining the effect of isolation and loneliness on physical function.

The importance of socioeconomic status

Another important consideration is that of socioeconomic status (SES). Socioeconomic disadvantage has been associated with lower physical functioning and greater 
disability. Social relationships may act as a buffer against the effects of low SES, in which case one would expect the effects of social relationships to be more pronounced amongst the socioeconomically disadvantaged. The Reserve Capacity Model (Gallo, de los Monteros, \& Shivpuri, 2009; Gallo \& Matthews, 2003) suggests that social and psychological resources may contribute to building up resilience among individuals of low SES, thereby attenuating inequalities in health. In testing this model, Schöllgen et al. found that greater social resources were associated with better self-rated health as well as a composite measure of physical health and functioning among individuals with low education but not amongst those with higher educational qualifications (Schöllgen, Huxhold, Schüz, \& Tesch-Römer, 2011). On the other hand, Unger et al. (1999) did not find that the effect of social ties on functional decline was moderated by income. The current analysis examined wealth as a moderator of the effect of isolation and loneliness on gait speed and number of ADLs. Wealth was chosen as a measure of SES as it may better reflect resources available to older adults when compared with education which is fixed earlier in life, or income which may not be appropriate for participants who are no longer working.

In summary, the present study used data from a nationally representative panel study of older adults to examine the effect of both social isolation and loneliness simultaneously on gait speed and difficulties with ADLs. It was hypothesized that both social isolation and loneliness would be prospectively associated with worsening gait speed and increasing difficulties with ADLs. No specific hypotheses were made regarding the relative size of the effects. It was also hypothesized that the effects of isolation and loneliness on these measures would be greater amongst those with less wealth.

\section{Method}




\section{Participants}

Data were obtained from waves 2 (2004/5) and 5 (2009/10) of the English Longitudinal Study of Ageing (ELSA), a nationally representative panel study of individuals aged 50 years or over, with biennial follow-up. Participants for ELSA were selected from respondents to the Health Surveys for England in 1998, 1999 and 2001. Further details regarding the study sample, data collection procedures and the cohort profile are available elsewhere (Steptoe, Breeze, Banks, \& Nazroo, 2013). Ethical approval for the ELSA study was provided by the London Multicentre Research Ethics Committee.

Wave 2 was used as baseline for these analyses as this is the first wave of ELSA that includes a measure of loneliness. Participants who dropped out after wave 1 of ELSA were of lower SES, less educated, in poorer health, more likely to be non-White, and less socially connected (Scholes, Taylor, Cheshire, Cox, \& Lessof, 2008; Shankar, McMunn, Banks, \& Steptoe, 2011). At each wave, the timed walk test was carried out only for participants aged 60 years and over. At baseline, complete data on gait speed were available for 5498 participants (89\% of core sample members aged 60 years and over). Follow-up data on gait speed were available for 3070 participants who formed the analytic sample. When compared with participants who dropped out after the baseline wave, the analytic sample was younger, wealthier, better educated, healthier, more socially connected and less lonely. Participants who dropped out also had lower gait speed and reported more problems with activities of daily living.

\section{Measures}

Measures of physical function were obtained in an identical manner at baseline and follow-up. 
Gait speed: A standard protocol was used where participants were required to walk a distance of 2.44 meters ( 8 feet) twice that was timed. The interviewer initially demonstrated the test. The participants were then instructed to walk at their usual pace and not race across the course. Participants were allowed to use a walking stick or a Zimmer frame if they normally used one. However, if the participant was unable to walk, required the support of another person to walk, did not feel it was safe to do the test or the interviewer judged that the test was unsafe for the participant, or if there was no suitable space to carry out the test, the timed walk test was not administered. The mean speed of the two walks $(\mathrm{m} / \mathrm{s})$ was taken as the measure of gait speed. If only a single valid value was available, this value was used.

Activities of daily living ( $A D L$ ): Participants were asked to report if they had difficulty with any of 6 activities of daily living including dressing, walking across a room, bathing or showering, eating, getting in or out of bed and using the toilet, with response options yes or no. Participants were instructed not to consider any difficulties that they expected would last less than 3 months. Responses to the items were summed to provide the total number of activities of daily living with which the participant had difficulties.

Measures of isolation, loneliness, wealth and all covariates were obtained at baseline only.

Social isolation: An index of social isolation was computed based on not married or living with a partner (scored as 1), less than monthly contact with other family, friends and children (each scored as 1), and non-participation in any social activities (scored as 1) (Shankar et al., 2011). Score ranged from 0 to 5 with higher scores indicating greater social isolation.

Loneliness: Loneliness was measured by summing responses on the 3-item Revised UCLA Loneliness Scale (Hughes, Waite, Hawkley, \& Cacioppo, 2004). Scores ranged from 3 
to 9, with higher scores indicating greater loneliness. The scale was found to have acceptable internal reliability (Cronbach’s $\alpha=0.79$ ).

Wealth: This refers to total (non-pension) wealth which was calculated net of debt and included the total value of the participant's home, other property, financial assets, business assets, jewelry, etc. (Banks, Karlssen, \& Oldfield, 2003).

Covariates: Details on age and gender were obtained from the core interview. Health status was measured using self-reports of doctor-diagnosed health conditions including cardiovascular disease (including arrhythmia, myocardial infarction, congestive heart failure, angina, heart murmur, diabetes, and stroke), cancer, chronic lung disease and arthritis. Depression was measured using the 8-item version of the Center for Epidemiologic Studies depression scale (Steffick, 2000). The item on loneliness was excluded (Cacioppo, Hawkley, \& Thisted, 2010) and responses were summed. Scores ranged from 0 to 7 , with higher scores indicating a greater number of depressive symptoms, and scores of 4 or higher indicate depressive caseness (Steffick, 2000). Educational level was coded as low, indicating participants with no formal qualifications (equivalent to no high school diploma in the United States) and high, including participants who had O-levels, A-levels or higher qualifications. The analysis additionally adjusted for health behaviors such as current smoking status and physical activity level. Current smoking status was measured by asking participants if they ever smoked. Participants who replied in the affirmative were then asked if they smoked at present. Responses to both questions were combined to form a current smoking status (yes/no) measure. A leisure-time physical activity measure asked participants about the frequency with which they took part in vigorous, moderate, or mild physical activity. In addition, individuals who were currently employed were asked whether their job was mainly sedentary standing, physical work or heavy manual work. Participants who reported moderate or vigorous leisure-time physical activity only once a week or less and if currently employed, 
were in a primarily sedentary occupation were classified as not meeting physical activity criteria. Participants reporting high levels of occupational physical activity and/or greater than once a week moderate/vigorous leisure time physical activity were classified as being physically active (Shankar, McMunn, \& Steptoe, 2010).

\section{Statistical analysis}

Missing data on predictors and covariates (for items imputed: median percentage missing $=0.26 \%$, mean $=1.9 \%$, maximum $=6.5 \%$ ) were imputed using the multiple imputation procedure in SAS (PROC MI). Five complete data sets were created and analyzed. Results for the analyses carried out on a sample where values were not imputed did not differ substantively from the analyses for the imputed data set, with the exception of the test for the interaction effects which were non-significant in the complete case analysis. The results of the analysis using the complete (imputed) data set are reported here.

As the wealth variable was skewed, it was log-transformed prior to analysis. Associations between isolation, loneliness and covariates were examined using bivariate regression analyses and results are presented as standardized regression coefficients $(\beta)$ with corresponding p-values. Linear regression analysis was used to examine the association between social isolation and loneliness at baseline and gait speed at follow-up. Results are presented using unstandardized regression coefficients (B) with corresponding standard errors (S.E.) and standardized regression coefficients ( $\beta$ ). As ADL scores represent count data, with some evidence of over-dispersion, we used a negative binomial regression with a log-link to predict ADL values at follow-up. Results are presented as incidence rate ratios (IRR) with corresponding 95\% confidence intervals. 
Four models were run for each outcome. Model 1 included all covariates and baseline levels of the outcome under consideration. Isolation and loneliness were added in Model 2. Model 3(a) included the addition of the isolation*wealth interaction to Model 2, while Model 3(b) included the addition of the loneliness*wealth interaction to Model 2. To aid the interpretation of significant interactions, MODPROBE was used to obtain predicted values of the outcome variable at different levels of the moderator (median, $25^{\text {th }}$ percentile and $75^{\text {th }}$ percentile). Analyses were carried out using SPSS 22.0 and SAS v 9.4 (SAS Institute, Cary, NC).

\section{Results}

The mean age of participants included in these analyses was 69 years, over half were women and just over a third reported having no formal educational qualifications (see Table 1). Approximately 8\% of participants reported ever having cancer. Diagnosed CVD was reported by $29.1 \%$ of the participants and just under $40 \%$ had arthritis. Chronic lung disease was reported by over $6 \%$ of participants. Nearly $11 \%$ of individuals identified themselves as current smokers and a quarter reported low levels of physical activity. About $10 \%$ of participants had a score of 4 and higher on the CESD which is indicative of depression. Only a small proportion of participants reported the highest possible scores on either the loneliness or the isolation measure. Gait speed declined significantly over the 6-year period ( $p<0.001)$, while the number of individuals reporting more than 1 difficulty with ADLs increased $(\mathrm{p}<$ $0.001)$.

Relationship with covariates 
Age was positively associated with isolation $(\beta=0.11, \mathrm{p}<0.001)$ and loneliness $(\beta=$ 0.09, $\mathrm{p}<0.001)$. Gender was not significantly associated with isolation $(\beta=-0.01, \mathrm{p}=0.48)$, but women reported higher levels of loneliness when compared with men $(\beta=0.11, \mathrm{p}<$ 0.001). Higher levels of isolation and loneliness were reported by individuals with diagnosed $\operatorname{CVD}(\beta=0.05, \mathrm{p}=0.005$ for isolation; $\beta=0.07, \mathrm{p}<0.001$ for loneliness $)$, lung disease $(\beta=$ 0.04, $\mathrm{p}<0.05$ for isolation; $\beta=0.09, \mathrm{p}<0.001$ for loneliness), and with CESD scores of 4 or higher ( $\beta=0.13$, $\mathrm{p}<0.001$ for isolation; $\beta=0.35, \mathrm{p}<0.001$ for loneliness). Arthritis was associated with higher levels of loneliness $(\beta=0.14, \mathrm{p}<0.001)$ but not isolation $(\beta=0.04$, $\mathrm{p}$ $=0.052$ ). However, diagnosis of cancer was not associated with greater isolation or loneliness ( $\beta=0.002, \mathrm{p}=0.92$ for isolation; $\beta=0.01, \mathrm{p}=0.69$ for loneliness). Having no formal educational qualifications $(\beta=0.17, \mathrm{p}<0.001)$ and decreasing wealth $(\beta=-0.26, \mathrm{p}<0.001)$ were also associated with higher levels of isolation. A similar pattern was found for loneliness ( $\beta=0.12, \mathrm{p}<0.001$ for education; $\beta=-0.21, \mathrm{p}<0.001$ for wealth). Being a smoker and reporting low levels of physical activity were both associated with greater isolation $(\beta=0.13$, $\mathrm{p}<0.001$ for smoking; $\beta=0.10, \mathrm{p}<0.001$ for physical activity) and loneliness $(\beta=0.08, \mathrm{p}<$ 0.001 for smoking; $\beta=0.14, \mathrm{p}<0.001$ for physical activity).

\section{Relationship between social isolation and loneliness}

Being isolated was associated with higher levels of loneliness ( $\mathrm{B}=0.34,95 \% \mathrm{CI}: 0.30$ to $0.38, \beta=0.31$ ). After adjustment for age, gender, health conditions, wealth, education and depression this association was partially attenuated, although still significant $(B=0.27$, 95\%CI: 0.24 to $0.31 ; \beta=0.24)$. 
Social isolation, loneliness and gait speed at follow-up

In a model including only covariates and baseline gait speed, all covariates except for diagnosed cancer and current smoking status were significantly associated with change in gait speed. Isolation and loneliness were added in Model 2, but neither was significantly associated with gait speed at follow-up.

Social isolation, loneliness and difficulties with ADLs at follow-up

In the covariate only model (Table 3, Model 1) all covariates with the exception of gender, educational level, cancer diagnosis, and current smoking status were associated with change in the number of difficulties with ADLs over time. Isolation and loneliness were added in the following model. A unit increase in loneliness score was associated with a 1.08 times increase in the incidence rate of number of ADLs. Isolation was not associated with change in number of ADLs.

\section{Moderation by wealth}

Both the isolation*wealth (Table 2, Model 3(a)) and the loneliness*wealth (Table 2, Model 3(b)) interactions were found to be significant in the analysis for gait speed. As seen in Figure 1, panels A and B, baseline isolation and loneliness had little effect on gait speed among the wealthiest participants. As levels of disadvantage increased, however, the effect of isolation and loneliness grew stronger such that individuals who were most disadvantaged showed the most marked decreases in gait speed with increasing levels of isolation and loneliness. 
Wealth did not significantly moderate the effect of loneliness and isolation on difficulties with ADLs.

\section{Discussion}

This one of few studies to examine the association of both structural and functional aspects of social relationships with measures of functional status. The analysis also assessed both an objective and a subjective measure of functional status, enabling us to examine the differential association of isolation and loneliness on these measures. Our findings show that both isolation and loneliness were important for declines in gait speed over the 6-year period, particularly as levels of socioeconomic disadvantage increased. Loneliness, but not isolation, was associated with an increase in reported difficulties with activities of daily living over a 6year period. These effects were independent of depression and other health related factors.

The Reserve Capacity Model suggests that social and psychological variables are particularly important among individuals who are more disadvantaged as they may help buffer the effects of a lack of material resources (Gallo, de los Monterors \& Shivpuri, 2009). As objective tests such as gait speed may reveal declines in health before the participant actually experiences difficulties in daily activities (Rozzini, Frisoni, Bianchetti, Zanetti, \& Trabucchi, 1993), it is possible that early intervention and better healthcare might have an important role to play in preventing such decline. Wealthy individuals are better able to access health care and other preventive measures, and hence may be less reliant on informal sources of support. In contrast, social networks might represent an important or even the main source of information and help for those who have fewer material resources. This also relates to the 'added value' hypothesis, such that social relationships may be more important to, and hence represent greater value for more disadvantaged groups (Vitaliano et al., 2001). At low 
levels of isolation and loneliness, wealthier participants report faster gait speed than poorer individuals $\left(0.85 \mathrm{~m} / \mathrm{s}\right.$ for the $75^{\text {th }}$ percentile vs $0.83 \mathrm{~m} / \mathrm{s}$ for the $25^{\text {th }}$ percentile), and this gap widened with increasing levels of isolation and loneliness. At the highest scores of isolation and loneliness, there was virtually no change in gait speed for the wealthy participants $(0.85$ $\mathrm{m} / \mathrm{s}$ for the $75^{\text {th }}$ percentile), while poorer participants showed marked decreases $(0.80 \mathrm{~m} / \mathrm{s}$ for the $25^{\text {th }}$ percentile). A gait speed of less than $0.80 \mathrm{~m} / \mathrm{s}$ may be associated with a reduced ability to move about freely in the community (Fritz \& Lusardi, 2009). Further, among community dwelling adults, a change $0.03-0.05 \mathrm{~m} / \mathrm{s}$ in walking speed would be regarded as clinically meaningful (Kwon et al., 2009; Perera, Mody, Woodman, \& Studenski, 2006). Thus, reducing isolation and loneliness among the most socioeconomically deprived older adults may have important implications for functional status.

Loneliness was also associated with self-reported disability. Previous research has indicated that variables such as neuroticism, low self-efficacy and low sense of control that are closely associated with loneliness (Cohen-Mansfield, Hazan, Lerman, \& Shalom, 2015; Mund \& Neyer, 2015; Newall et al., 2009), are also associated with subjective measures of functional status (Clarke \& Smith, 2011; Duberstein et al., 2003; Jang, Mortimer, Haley, \& Graves, 2002; Kempen, Sonderen, \& Ormel, 1999) over time. Feelings of loneliness may serve to exacerbate existing vulnerabilities in health leading to disability, either through poor health behaviors or through the inflammatory or cardiovascular pathway (Cacioppo \& Hawkley, 2003; Cacioppo et al., 2002; Hawkley \& Cacioppo, 2003) . Findings in this area are, however, equivocal and more research is required to determine the precise mechanisms through which loneliness may affect health.

\section{Study strengths and limitations}


The current analyses used data from a large, nationally representative, multidisciplinary panel study of older adults. Hence, it was possibe to obtain not only objective assessments of physical function which were measured using a standardized protocol by trained professionals, but also subjective assessments of disability and detailed information on individuals' financial circumstances. The analyses were adjusted for a variety of confounding health, socioeconomic and psychosocial factors. Notwithstanding, these are observational data and causation cannot be inferred. Further, measures of health behaviors were self-reported and hence may have been incorrectly estimated. At baseline $55.2 \%$ of the sample reported the lowest possible scores on loneliness, while $45.4 \%$ reported the lowest possible scores on the 7-item depression measure, suggesting floor effects. The present analysis used the short form of the CES-D and a different measure may have provided a more comprehensive assessment of depression in this population. One of the main limitations in this study is that of drop out. The sample analyzed here was healthier, wealthier, more socially connected and less lonely when compared with those who had dropped out. Further, measures of gait speed were not obtained for participants who were very frail or those for whom it was judged unsafe. Thus these findings may represent a conservative estimate of the true associations and as such be generalizable to relatively healthy older adults.

\section{Conclusions}

These findings indicate differences in determinants of objective and subjective disability and further illustrate the need to examine both isolation and loneliness as distinct risk factors for poor health outcomes. The findings highlight the need to address issues of isolation and loneliness among older adults to help them maintain physical functioning as they age. It may be useful to direct intervention efforts at individuals from disadvantaged 
backgrounds who are also at high risk of being isolated or lonely (e.g. those who are recently bereaved) or those who may be particularly vulnerable to functional decline. 


\section{References}

Abellan Van Kan, G., Rolland, Y., Andrieu, S., Bauer, J., Beauchet, O., Bonnefoy, M., . . . Vellas, B. (2010). Gait speed at usual pace as a predictor of adverse outcomes in community-dwelling older people an International Academy on Nutrition and Aging (IANA) Task Force. The journal of nutrition, health \& aging, 13(10), 881-889. doi:10.1007/s12603-009-0246-z

Avlund, K., Lund, R., Holstein, B. E., Due, P., Sakari-Rantala, R., \& Heikkinen, R.-L. (2004). The Impact of Structural and Functional Characteristics of Social Relations as Determinants of Functional Decline. The Journals of Gerontology Series B: Psychological Sciences and Social Sciences, 59(1), S44-S51. doi:10.1093/geronb/59.1.S44

Banks, J., Karlssen, S., \& Oldfield, Z. (2003). Socio-economic position. In M. Marmot, J. Banks, J. Blundell, C. Lessof, \& J. Nazroo (Eds.), Health, wealth and lifestyles of the older population in England: The 2002 English Longitudinal Study of Ageing. London: The Institute for Fiscal Studies

Beaumont, J. (2013). Measuring national well-being - Older people and loneliness, 2013. Retrieved from http://www.ons.gov.uk/ons/dcp171766_304939.pdf

Brach, J. S., FitzGerald, S., Newman, A. B., \& et al. (2003). Physical activity and functional status in community-dwelling older women: A 14-year prospective study. Archives of Internal Medicine, 163(21), 2565-2571. doi:10.1001/archinte.163.21.2565

Brown, C. J., \& Flood, K. L. (2013). Mobility limitation in the older patient: A clinical review. JAMA, 310(11), 1168-1177. doi:10.1001/jama.2013.276566

Buchman, A. S., Boyle, P. A., Wilson, R. S., Fleischman, D. A., Leurgans, S., \& Bennett, D. A. (2009). Association between late-life social activity and motor decline in older 
adults. Archives of Internal Medicine, 169(12), 1139-1146.

doi:10.1001/archinternmed.2009.135

Buchman, A. S., Boyle, P. A., Wilson, R. S., James, B. D., Leurgans, S. E., Arnold, S. E., \& Bennett, D. A. (2010). Loneliness and the rate of motor decline in old age: the Rush Memory and Aging Project, a community-based cohort study. BMC Geriatrics, 10, 77. Cacioppo, J. T., \& Hawkley, L. C. (2003). Social Isolation and Health, with an Emphasis on Underlying Mechanisms. Perspectives in Biology and Medicine, 46(3x), S39-S52.

Cacioppo, J. T., Hawkley, L. C., \& Thisted, R. A. (2010). Perceived Social Isolation Makes Me Sad: Five Year Cross-Lagged Analyses of Loneliness and Depressive Symptomatology in the Chicago Health, Aging, and Social Relations Study. Psychology and Aging, 25(2), 453-463. doi:10.1037/a0017216

Cacioppo, J. T., Hawkley, L. C. M. A., Crawford, L. E. P., Ernst, J. M. P., Burleson, M. H. P., Kowalewski, R. B. M. A., .. . Berntson, G. G. P. (2002). Loneliness and Health: Potential Mechanisms. Psychosomatic Medicine May/June, 64(3), 407-417.

Christensen, K., McGue, M., Petersen, I., Jeune, B., \& Vaupel, J. W. (2008). Exceptional longevity does not result in excessive levels of disability. Proceedings of the National Academy of Sciences, 105(36), 13274-13279. doi:10.1073/pnas.0804931105

Clarke, P., \& Smith, J. (2011). Aging in a Cultural Context: Cross-national Differences in Disability and the Moderating Role of Personal Control Among Older Adults in the United States and England. The Journals of Gerontology Series B: Psychological Sciences and Social Sciences, 66B(4), 457-467. doi:10.1093/geronb/gbr054

Cohen-Mansfield, J., Hazan, H., Lerman, Y., \& Shalom, V. (2015). Correlates and predictors of loneliness in older-adults: a review of quantitative results informed by qualitative insights. International Psychogeriatrics, FirstView, 1-20.

doi:doi:10.1017/S1041610215001532 
Cooper, R., Kuh, D., Cooper, C., Gale, C. R., Lawlor, D. A., Matthews, F., . . . Teams, T. F. a. H. S. (2011). Objective measures of physical capability and subsequent health: a systematic review. Age and Ageing, 40(1), 14-23. doi:10.1093/ageing/afq117

Courtin, E., \& Knapp, M. (2015). Social isolation, loneliness and health in old age: a scoping review. Health \& Social Care in the Community, n/a-n/a. doi:10.1111/hsc.12311

Cruz-Jentoft, A. J., Baeyens, J. P., Bauer, J. M., Boirie, Y., Cederholm, T., Landi, F., . . . Zamboni, M. (2010). Sarcopenia: European consensus on definition and diagnosis: Report of the European Working Group on Sarcopenia in Older People. Age and Ageing, 39(4), 412-423. doi:10.1093/ageing/afq034

Demakakos, P., Cooper, R., Hamer, M., de Oliveira, C., Hardy, R., \& Breeze, E. (2013). The Bidirectional Association between Depressive Symptoms and Gait Speed: Evidence from the English Longitudinal Study of Ageing (ELSA). PLoS ONE, 8(7), e68632. doi:10.1371/journal.pone.0068632

Duberstein, P. R., S+Ârensen, S., Lyness, J. M., King, D. A., Conwell, Y., Seidlitz, L., \& Caine, E. D. (2003). Personality is associated with perceived health and functional status in older primary care patients. Psychology and Aging, 18(1), 25-37. doi:doi:10.1037/0882-7974.18.1.25

Fritz, S., \& Lusardi, M. (2009). White Paper: "Walking Speed: the Sixth Vital Sign". Journal of Geriatric Physical Therapy, 32(2), 2-5.

Gallo, L. C., de los Monteros, K. E., \& Shivpuri, S. (2009). Socioeconomic Status and Health: What is the role of Reserve Capacity? Current directions in psychological science, 18(5), 269-274.

Gallo, L. C., \& Matthews, K. A. (2003). Understanding the association between socioeconomic status and physical health: Do negative emotions play a role? . Psychological Bulletin, 129(1), 10-51. 
Green, A. F., Rebok, G., \& Lyketsos, C. G. (2008). Influence of social network characteristics on cognition and functional status with aging. International Journal of Geriatric Psychiatry, 23(9), 972-978. doi:10.1002/gps.2023

Guralnik, J. M., Butterworth, S., Patel, K., Mishra, G., \& Kuh, D. (2009). Reduced Midlife Physical Functioning Among Never Married and Childless Men: Evidence from the 1946 British Birth Cohort Study. Aging clinical and experimental research, 21(2), $174-181$.

Guralnik, J. M., \& Ferrucci, L. (2003). Assessing the building blocks of function: Utilizing measures of functional limitation. American Journal of Preventive Medicine, 25(3, Supplement 2), 112-121. doi:http://dx.doi.org/10.1016/S0749-3797(03)00174-0

Hawkley, L. C., \& Cacioppo, J. T. (2003). Loneliness and pathways to disease. Brain, Behavior, and Immunity, 17(1, Supplement), 98-105. doi:http://dx.doi.org/10.1016/S0889-1591(02)00073-9

Hoeymans, N., Feskens, E. J. M., van den Bos, G. A. M., \& Kromhout, D. (1996). Measuring functional status: Cross-sectional and longitudinal associations between performance and self-report (Zutphen Elderly Study 1990-1993). Journal of Clinical Epidemiology, 49(10), 1103-1110. doi:http://dx.doi.org/10.1016/0895-4356(96)00210$\underline{7}$

Holt-Lunstad, J., Smith, T. B., Baker, M., Harris, T., \& Stephenson, D. (2015). Loneliness and Social Isolation as Risk Factors for Mortality: A Meta-Analytic Review. Perspectives on Psychological Science, 10(2), 227-237. doi:10.1177/1745691614568352

Holt-Lunstad, J., Smith, T. B., \& Layton, J. B. (2010). Social Relationships and Mortality Risk: A Meta-analytic Review. PLoS Med, 7(7), e1000316. doi:10.1371/journal.pmed.1000316 
Hughes, M. E., Waite, L. J., Hawkley, L. C., \& Cacioppo, J. T. (2004). A Short Scale for Measuring Loneliness in Large Surveys: Results From Two Population-Based Studies. Research on aging, 26(6), 655-672. doi:10.1177/0164027504268574

Jang, Y., Mortimer, J. A., Haley, W. E., \& Graves, A. B. (2002). The Role of Neuroticism in the Association Between Performance-Based and Self-Reported Measures of Mobility. Journal of Aging and Health, 14(4), 495-508.

Jivraj, S., Nazroo, J., \& Barnes, M. (2012). Changes in social detachment in older age in England (J. N. Banks, J; Steptoe, A Ed.). London: Institute for Fiscal Studies.

Kanamori, S., Kai, Y., Aida, J., Kondo, K., Kawachi, I., Hirai, H., . . The, J. G. (2014). Social Participation and the Prevention of Functional Disability in Older Japanese: The JAGES Cohort Study. PLoS ONE, 9(6), e99638. doi:10.1371/journal.pone.0099638

Kempen, G. I. J. M., Sonderen, E. v., \& Ormel, J. (1999). The Impact of Psychological Attributes on Changes in Disability Among Low-Functioning Older Persons. The Journals of Gerontology Series B: Psychological Sciences and Social Sciences, 54B(1), P23-P29. doi:10.1093/geronb/54B.1.P23

Kivinen, P., Sulkava, R., Halonen, P., \& Nissinen, A. (1998). Self-Reported and PerformanceBased Functional Status and Associated Factors Among Elderly Men: The Finnish Cohorts of the Seven Countries Study. Journal of Clinical Epidemiology, 51(12), 1243-1252. doi:http://dx.doi.org/10.1016/S0895-4356(98)00115-2

Kwon, S., Perera, S., Pahor, M., Katula, J. A., King, A. C., Groessl, E. J., \& Studenski, S. A. (2009). What is a meaningful change in physical performance? Findings from a clinical trial in older adults (the LIFE-P study). JNHA - The Journal of Nutrition, Health and Aging, 13(6), 538-544. doi:10.1007/s12603-009-0104-z 
Lee, Y. (2000). The predictive value of self assessed general, physical, and mental health on functional decline and mortality in older adults. Journal of Epidemiology and Community Health, 54(2), 123-129. doi:10.1136/jech.54.2.123

Mund, M., \& Neyer, F. J. (2015). The Winding Paths of the Lonesome Cowboy: Evidence for Mutual Influences Between Personality, Subjective Health, and Loneliness. Journal of Personality, n/a-n/a. doi:10.1111/jopy.12188

Nagi, S. Z. (1976). An epidemiology of disability among adults in the United States. The Milbank Memorial Fund Quarterly. Health and Society, 54(4).

Newall, N. E., Chipperfield, J. G., Clifton, R. A., Perry, R. P., Swift, A. U., \& Ruthig, J. C. (2009). Causal beliefs, social participation, and loneliness among older adults: A longitudinal study. Journal of Social and Personal Relationships, 26(2-3), 273-290. doi:10.1177/0265407509106718

North, T.-L., Palmer, T. M., Lewis, S. J., Cooper, R., Power, C., Pattie, A., . . Day, I. N. M. (2015). Effect of smoking on physical and cognitive capability in later life: a multicohort study using observational and genetic approaches. BMJ Open, 5(12), e008393. doi:10.1136/bmjopen-2015-008393

Office for National Statistics. (2013). What does the 2011 Census tell us about older people? . Retrieved from http://www.ons.gov.uk/ons/rel/census/2011-census-analysis/whatdoes-the-2011-census-tell-us-about-older-people-/what-does-the-2011-census-tell-usabout-older-people--short-story.html

Perera, S., Mody, S. H., Woodman, R. C., \& Studenski, S. A. (2006). Meaningful Change and Responsiveness in Common Physical Performance Measures in Older Adults. Journal of the American Geriatrics Society, 54(5), 743-749. doi:10.1111/j.15325415.2006.00701.X 
Perissinotto, C. M., Stijacic, C., I, \& Covinsky, K. E. (2012). Loneliness in older persons: a predictor of functional decline and death. Archives of Internal Medicine, 172(14), 1078-1083.

Reuben, D. B., Seeman, T. E., Keeler, E., Hayes, R. P., Bowman, L., Sewall, A., . . . Guralnik, J. M. (2004). Refining the Categorization of Physical Functional Status: The Added Value of Combining Self-Reported and Performance-Based Measures. The Journals of Gerontology Series A: Biological Sciences and Medical Sciences, 59(10), M1056-M1061.

Rozzini, R., Frisoni, G. B., Bianchetti, A., Zanetti, O., \& Trabucchi, M. (1993). Physical Performance Test and Activities of Daily Living Scales in the Assessment of Health Status in Elderly People. Journal of the American Geriatrics Society, 41(10), 11091113. doi:10.1111/j.1532-5415.1993.tb06460.x

Rozzini, R., Frisoni, G. B., Ferrucci, L., Barbisoni, P., Bertozzi, B., \& Trabucchi, M. (1997). The effect of chronic diseases on physical function. Comparison between activities of daily living scales and the Physical Performance Test. Age and Ageing, 26(4), 281287.

Scholes, S., Taylor, R., Cheshire, H., Cox, K., \& Lessof, C. (2008). Technical report (ELSA wave 2): retirement, health and relationships of the older population in England. London: Institute for Fiscal Studies.

Schöllgen, I., Huxhold, O., Schüz, B., \& Tesch-Römer, C. (2011). Resources for health: Differential effects of optimistic self-beliefs and social support according to socioeconomic status. Health Psychology, 30, 326-335. doi:10.1037/a0022514

Shankar, A., McMunn, A., Banks, J., \& Steptoe, A. (2011). Loneliness, social isolation, and behavioral and biological health indicators in older adults. Health Psychology, 30(4), 377-385. doi:10.1037/a0022826 
Shankar, A., McMunn, A., \& Steptoe, A. (2010). Health-Related Behaviors in Older Adults: Relationships with Socioeconomic Status. American Journal of Preventive Medicine, 38(1), 39-46. doi:http://dx.doi.org/10.1016/j.amepre.2009.08.026

Steffick, D. E. (2000). Documentation of Affective Functioning Measures in the Health and Retirement Study. Retrieved from Ann Arbor:

Steptoe, A., Breeze, E., Banks, J., \& Nazroo, J. (2013). Cohort Profile: The English Longitudinal Study of Ageing. International Journal of Epidemiology, 42(6), 16401648. doi:10.1093/ije/dys168

Stessman, J., Rottenberg, Y., Shimshilashvili, I., Ein-Mor, E., \& Jacobs, J. M. (2013). Loneliness, Health, and Longevity. The Journals of Gerontology Series A: Biological Sciences and Medical Sciences. doi:10.1093/gerona/glt147

Studenski, S., Perera, S., Patel, K., Rosano, C., Faulkner, K., Inzitari, M., . . Guralnik, J. (2011). Gait Speed and Survival in Older Adults. JAMA : the journal of the American Medical Association, 305(1), 50-58. doi:10.1001/jama.2010.1923

Unger, J. B., McAvay, G., Bruce, M. L., Berkman, L., \& Seeman, T. (1999). Variation in the Impact of Social Network Characteristics on Physical Functioning in Elderly Persons: MacArthur Studies of Successful Aging. The Journals of Gerontology Series B: Psychological Sciences and Social Sciences, 54B(5), S245-S251. doi:10.1093/geronb/54B.5.S245

Vitaliano, P. P., Scanlan, J. M., Zhang, J., Savage, M. V., Brummett, B., Barefoot, J., \& Siegler, I. C. (2001). Are the salutogenic effects of social supports modified by income? A test of an "added value hypothesis". Health Psychology, 20(3), 155-165. doi:10.1037/0278-6133.20.3.155 
Wang, H., Chen, K., Pan, Y., Jing, F., \& Liu, H. (2013). Associations and Impact Factors between Living Arrangements and Functional Disability among Older Chinese Adults. PLoS ONE, 8(1), e53879. doi:10.1371/journal.pone.0053879 
Table 1. Characteristics of the study sample $(\mathrm{N}=3070)$

\begin{tabular}{|c|c|}
\hline Variable & Analytic sample \\
\hline Age in years - Mean (SD) & $69.0(6.6)$ \\
\hline Male (\%) & 44.2 \\
\hline Diagnosed CVD (\%) & 29.1 \\
\hline Diagnosed chronic lung disease (\%) & 6.5 \\
\hline Diagnosed cancer (\%) & 8.1 \\
\hline Diagnosed arthritis (\%) & 38.8 \\
\hline \multicolumn{2}{|l|}{ Depression } \\
\hline Mean (SD) & $1.2(1.6)$ \\
\hline Caseness - scores > $3(\%)$ & 10.1 \\
\hline No educational qualifications (\%) & 36.4 \\
\hline Wealth (GBP) - Median (Min-Max) & 213930 (120850-360010) \\
\hline Current smoker (\%) & 10.6 \\
\hline Inactive (\%) & 25.7 \\
\hline \multicolumn{2}{|l|}{ Isolation (range: 0 to 5) } \\
\hline Mean (SD) & $1.3(1.2)$ \\
\hline Reporting highest possible score (\%) & 3.4 \\
\hline \multicolumn{2}{|l|}{ Loneliness (range: 3 to 9) } \\
\hline Mean (SD) & $4.0(1.4)$ \\
\hline Reporting highest possible score (\%) & 1.2 \\
\hline \multicolumn{2}{|l|}{ Gait speed (m/s) } \\
\hline Baseline & $0.92(0.27)$ \\
\hline Follow-up & $0.83(0.27)$ \\
\hline
\end{tabular}


Problems with 1 or more ADLS (\%)

Baseline

Follow-up
15.5

18.8 
Table 2. Linear regression of gait speed at follow-up $(\mathrm{N}=3070)$

\begin{tabular}{|c|c|c|c|c|c|c|c|c|}
\hline & Mode & & Model 2 & & Model 3(a) & & Model 3(b) & \\
\hline & B (SE) & $\boldsymbol{\beta}$ & B (SE) & $\boldsymbol{\beta}$ & B (SE) & $\boldsymbol{\beta}$ & B (SE) & $\boldsymbol{\beta}$ \\
\hline Age & $-0.01(0.001)^{\dagger}$ & -0.23 & $-0.01(0.001)^{\dagger}$ & -0.23 & $-0.01(0.001)^{\dagger}$ & -0.23 & $-0.01(0.001)$ & -0.23 \\
\hline Male & $0.03(0.01)^{\dagger}$ & 0.05 & $0.03(0.01)^{* *}$ & 0.05 & $0.03(0.01)^{* *}$ & 0.05 & $0.03(0.01)$ & 0.05 \\
\hline CVD & $-0.03(0.01)^{\dagger}$ & -0.05 & $-0.03(0.01)^{\dagger}$ & -0.05 & $-0.03(0.01)^{\dagger}$ & -0.05 & $-0.03(0.01)$ & -0.05 \\
\hline Chronic lung disease & $-0.04(0.01)^{*}$ & -0.04 & $-0.04(0.01)^{* *}$ & -0.04 & $-0.04(0.01)^{* *}$ & -0.04 & $-0.04(0.02)$ & -0.04 \\
\hline Arthritis & $-0.03(0.01)^{\dagger}$ & -0.06 & $-0.03(0.01)^{\dagger}$ & -0.06 & $-0.01(0.01)^{\dagger}$ & -0.06 & $-0.03(0.01)$ & -0.06 \\
\hline Cancer & $-0.01(0.01)$ & -0.01 & $-0.01(0.01)$ & -0.01 & $-0.03(0.01)$ & -0.01 & $-0.01(0.01)$ & -0.01 \\
\hline Low educational level & $-0.03(0.01)^{\dagger}$ & -0.01 & $-0.03(0.01)^{\dagger}$ & -0.05 & $-0.03(0.01)^{\dagger}$ & -0.05 & $-0.03(0.01)$ & -0.05 \\
\hline Wealth $^{\ddagger}$ & $0.07(0.01)^{\dagger}$ & 0.10 & $0.07(0.01)^{\dagger}$ & 0.09 & $0.05(0.02)^{* *}$ & 0.06 & $0.01(0.03)$ & 0.02 \\
\hline Depression & $-0.03(0.01)^{*}$ & -0.03 & $-0.02(0.01)$ & -0.02 & $-0.02(0.01)$ & -0.02 & $-0.02(0.01)$ & -0.02 \\
\hline Current smoker & $-0.02(0.01)$ & -0.02 & $-0.02(0.01)$ & -0.01 & $-0.02(0.01)$ & -0.02 & $-0.02(0.01)$ & -0.02 \\
\hline Inactive & $-0.04(0.01)^{\dagger}$ & -0.07 & $-0.04(0.01)^{\dagger}$ & -0.06 & $-0.04(0.01)^{\dagger}$ & -0.06 & $-0.04(0.01)$ & -0.06 \\
\hline Baseline gait speed & $0.47(0.02)^{\dagger}$ & 0.46 & $0.47(0.02)^{\dagger}$ & 0.46 & $0.47(0.02)^{\dagger}$ & 0.46 & $0.47(0.01)$ & 0.46 \\
\hline Isolation & & & $-0.01(0.003)$ & -0.02 & $-0.08(0.04)^{*}$ & -0.40 & $-0.01(0.003)$ & -0.02 \\
\hline
\end{tabular}




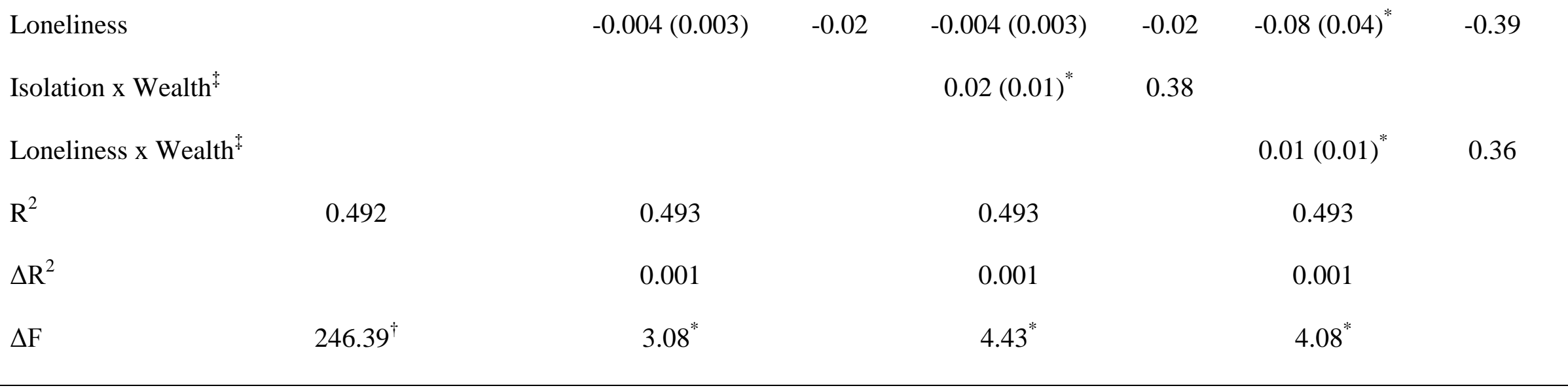

\section{${ }^{\ddagger}$ Log-transformed}

${ }^{\dagger} \mathrm{p}<0.001 ;{ }^{* *} \mathrm{p}<0.01 ;{ }^{*} \mathrm{p}<0.05$ 
Table 3. Negative binomial regression of number of difficulties with Activities of Daily Living at follow-up $(\mathrm{N}=3070)$

\begin{tabular}{|c|c|c|c|c|}
\hline & Model 1 & Model 2 & Model 3(a) & Model 3(b) \\
\hline & IRR (95\% CI) & IRR (95\% CI) & IRR (95\% CI) & IRR (95\% CI) \\
\hline Age & $1.04(1.03-1.06)^{\dagger}$ & $1.04(1.03-1.05)^{\dagger}$ & $1.04(1.03-1.05)^{\dagger}$ & $1.04(1.03-1.05)^{\dagger}$ \\
\hline Male & $0.98(0.82-1.17)$ & $0.96(0.81-1.15)$ & $0.96(0.81-1.15)$ & $0.96(0.81-1.15)$ \\
\hline CVD & $1.28(1.07-1.53)^{* *}$ & $1.28(1.07-1.53)^{* *}$ & $1.28(1.07-1.53)^{* *}$ & $1.28(1.07-1.53)^{* *}$ \\
\hline Chronic lung disease & $1.52(1.14-2.02)^{* *}$ & $1.48(1.11-1.96)^{* *}$ & $1.47(1.11-1.96)^{* *}$ & $1.48(1.11-1.97)^{* *}$ \\
\hline Arthritis & $1.84(1.54-2.19)^{\dagger}$ & $1.81(1.51-2.16)^{\dagger}$ & $1.81(1.51-2.16)^{\dagger}$ & $1.81(1.51-2.16)^{\dagger}$ \\
\hline Cancer & $1.19(0.89-1.59)$ & $1.19(0.89-1.60)$ & $1.19(0.89-1.60)$ & $1.19(0.89-1.60)$ \\
\hline Low educational level & $0.92(0.77-1.11)$ & $0.94(0.79-1.13)$ & $0.94(0.79-1.13)$ & $0.94(0.79-1.13)$ \\
\hline Wealth $^{\ddagger}$ & $0.76(0.59-0.96)^{*}$ & $0.76(0.59-0.97)^{*}$ & $0.73(0.51-1.05)$ & $0.75(0.39-1.42)$ \\
\hline Depression & $1.59(1.26-2.01)^{\dagger}$ & $1.44(1.13-1.85)^{* *}$ & $1.44(1.13-1.85)^{* *}$ & $1.44(1.13-1.85)^{* *}$ \\
\hline Current smoker & $1.14(0.88-1.49)$ & $1.14(0.88-1.48)$ & $1.14(0.87-1.48)$ & $1.14(0.87-1.48)$ \\
\hline Inactive & $1.38(1.15-1.66)^{\dagger}$ & $1.37(1.15-1.66)^{\dagger}$ & $1.38(1.15-1.66)^{\dagger}$ & $1.38(1.15-1.66)^{\dagger}$ \\
\hline Baseline difficulties & $1.72(1.55-1.89)^{\dagger}$ & $1.70(1.54-1.88)^{\dagger}$ & $1.71(1.55-1.88)^{\dagger}$ & $1.71(1.54-1.88)^{\dagger}$ \\
\hline
\end{tabular}


Isolation

Loneliness

Isolation x Wealth ${ }^{\ddagger}$

Loneliness x Wealth ${ }^{\ddagger}$
$0.83(0.34-2.06)$

$1.08(1.02-1.15)^{*}$

$1.03(0.86-1.22)$
$0.96(0.88-1.02)$

$1.06(0.52-2.15)$

$1.00(0.88-1.15)$

${ }^{\ddagger}$ Log-transformed

${ }^{\dagger} \mathrm{p}<0.001 ;{ }^{* *} \mathrm{p}<0.01 ;{ }^{*} \mathrm{p}<0.05$ 
Figure 1. Follow-up gait speed by levels of isolation and wealth (A) and loneliness and wealth (B)

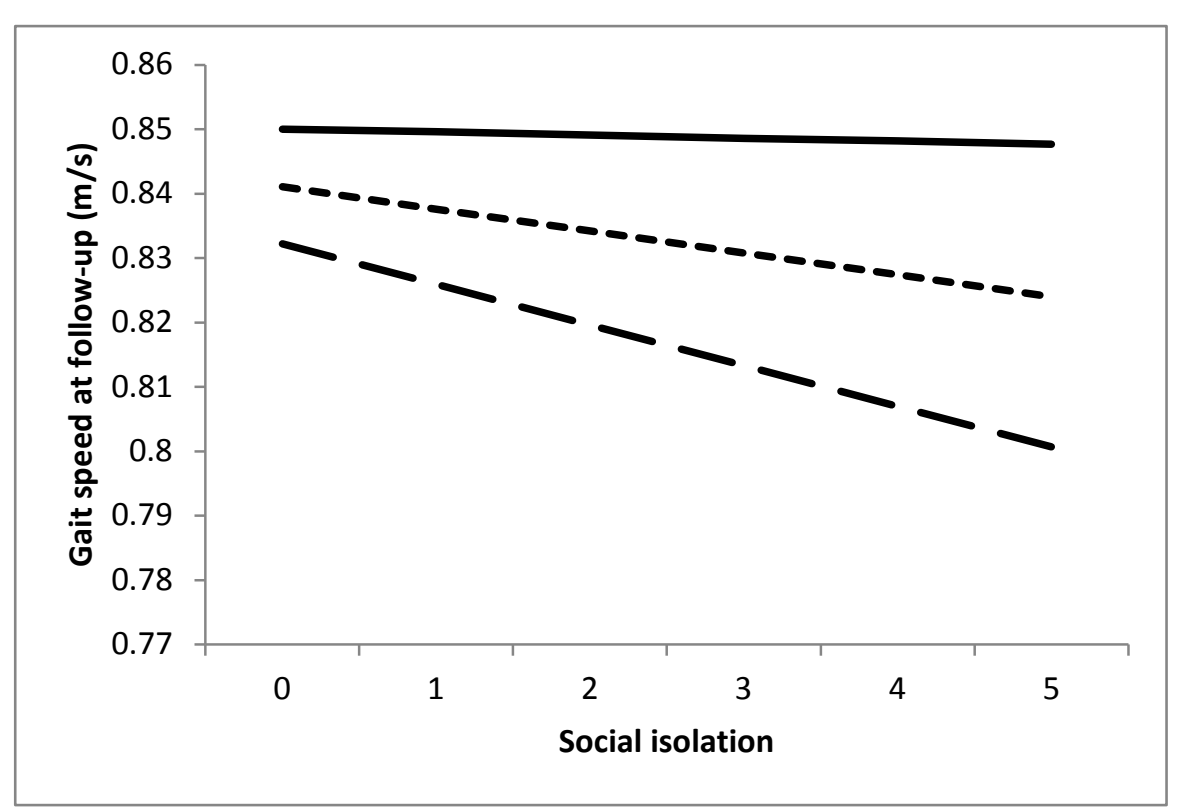

(A)

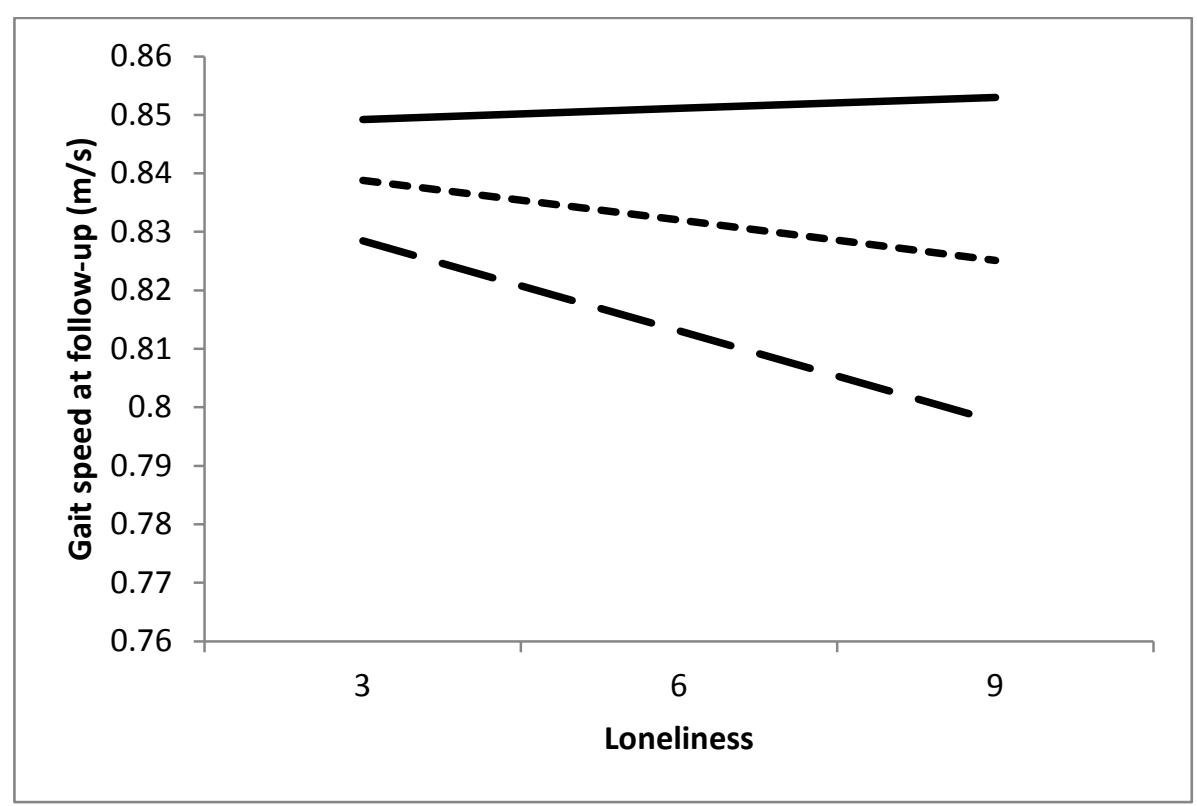

(B)

$25^{\text {th }}$ percentile of wealth $50^{\text {th }}$ percentile of wealth (median)

- $-75^{\text {th }}$ percentile of wealth

Values adjusted for age, gender, diagnosed CVD, diagnosed cancer, diagnosed chronic lung disease, diagnosed arthritis, CESD caseness, educational level, current smoking status, physical activity and baseline gait speed. 